\title{
Analisa Isolasi Pipa Generator Mesin Stirling Tipe Alpha Sudut Fasa 180
}

\author{
Dhimas Satria $^{1 *}$, Rina Lusiani ${ }^{1}$, Erny Listijorini $^{1}$, Aswata $^{1}$ \\ *Email corresponding author: dhimas@untirta.ac.id
}

${ }^{1}$ Teknik Mesin, Universitas Sultan Ageng Tirtayasa, Jl. Jenderal Sudirman km. 3, Cilegon, Banten

Article history: Received: 20 November 2020 | Revised: 26 April 2021 | Accepted: 17 Mei 2021

\begin{abstract}
This research is a development of previous research, where in the previous research, a design innovation was carried out on an alpha-type stirling engine by making the phase angle to $180^{\circ}$, with the aim of reducing the effect when the cold cylinder is compressed, because the phase angle currently used is $\left(90^{\circ}\right)$ with disadvantages, namely the cold cylinder is perpendicular to the top, so that the compression process against gravity. But in previous studies, the generator pipe was too long, causing a lot of energy or heat loss (heat loss) so that the compression speed was small. So that in the research, innovated and analyzed the pipe insulation of alpha-type stirling engine generators, alpha-type stirling engines, $180^{\circ}$ phase angle. The research method used is to use the thermodynamic approach with Schmidt theory and the theory of the ideal cycle stirling engine. while the simulation is done using the Ideal Stirling Cycle Calculator. Results investigated shows that providing insulation on the generator pipes of an alpha-type stirling engine for an alpha-type stirling engine with a $180^{\circ}$ phase angle is proven to reduce a lot of energy or heat loss (heat loss) due to too long generator pipes, with a heat loss value ratio of $226.66 \mathrm{~W}$ for the pipe. generator that uses insulation whose value is smaller than the value of the heat loss when the generator pipe without using isocation is 1,584.12 W.
\end{abstract}

Keywords - stirling machine, generator pipe, isolation, heat loss

Abstrak. Penelitian ini merupakan pengembangan dari penelitian sebelumnya, dimana pada penelitian sebelumnya dilakukan inovasi desain pada mesin stirling tipe alpha dengan membuat sudut fasa menjadi $180^{\circ}$, dengan tujuan untuk mengurangi pengaruh gravitasi pada saat silinder dingin terkompresi, karena sudut fasa yang sekarang digunakan $\left(90^{\circ}\right)$ memiliki kekurangan yaitu silinder dinginnya yang tegak lurus ke atas, sehingga proses kompresinya melawan gravitasi. Tetapi pada penelitian sebelumnya memiliki kekurangan yaitu pipa generator yang terlalu panjang sehingga menyebabkan banyak kehilangan energi atau panas (heat loss) sehingga kecepatan kompresi menjadi kecil. Sehingga pada penelitian ini melakukan inovasi dan analisa isolasi pipa generator mesin stirling tipe alpha mesin stirling tipe alpha sudut fasa $180^{\circ}$. Metode penelitian yang digunakan yaitu menggunakan metode pendekatan termodinamika dengan teori Schmidt dan teori siklus ideal mesin stirling. sementara Simulasi dilakukan dengan menggunakan Ideal Stirling Cycle Calculator. Hasil penelitian menunjukkan bahwa pemberian isolasi pada pipa generator mesin stirling tipe alpha mesin stirling tipe alpha sudut fasa $180^{\circ}$ terbukti dapat mengurangi banyak kehilangan energi atau panas (heat loss) akibat pipa generator yang terlalu panjang, dengan perbandingan nilai heat loss 226,66 W untuk pipa generator yang menggunakan isolasi yang nilainya juah lebih kecil dibandingkan nilai heat loss ketika pipa generator tanpa menggunakan isokasi yaitu 1.584,12 W.

Kata Kunci - mesin stirling, pipa generator, isolasi, heat loss

\section{Pendahuluan}

Energi fosil dieksplorasi secara besar-besaran dan tidak sebanding dengan waktu pembentukan energi fosil tersebut sehingga akan menyebabkan energy fosil akan habis di kemudian hari [1], [2]. Upaya untuk mengatasi permasalahan energi tersebut adalah dengan menggunakan sumber-sumber energi selain fosil, yang mudah didapatkan dan dapat dipebarui. Di sisi lain, limbah sampah juga menjadi permasalahan tersendiri terkait pengelolaannya. Dunia kampus merupakan salah satu penyumbang sampah terbesar dalam suatu kota. Dengan 'penduduk' tetap yang selalu berada di kampus yang memiliki aktivitas rutin, bahkan di hari libur, tentu saja menghasilkan berbagai jenis sampah setiap harinya. Sampah yang dihasilkan dapat dibagi menjadi 3 kategori berdasarkan tujuan pengolahan akhirnya, yaitu sampah organik, sampah yang dapat didaur ulang, dan sampah tidak dapat didaur ulang. Sampah-sampah ini dapat diperoleh oleh mahasiswa baik dari dalam maupun luar kampus. Namun, dibuang di dalam kampus. Sampah organik berasal dari sisa-sisa makanan atau jajanan para mahasiswa atau pun sisa-sisa masakan dari kantin atau warung makan serta sampah rumput dan tanaman dari taman yang berada lingkungan kampus. Sampah yang dapat didaur ulang merupakan berbagai jenis sampah yang terdiri dari plastik, kertas, kaleng, kardus, dan jenis-jenis sampah lain yang dapat dimanfaatkan kembali atau didaur ulang. Sampah 
yang tidak dapat didaur ulang merupakan sampah lainnya di luar sampah makanan dan sampah yang dapat didaur ulang.

Salah satu pengelolaan yang dapat meminimalkan penumpukan sampah di kampus adalah dengan memanfaatkan kembali sampah tersebut menjadi sesuatu yang bermanfaat. Jika dikaitkan dengan permasalahan energi yang telah disebut sebelumnya, yaitu semakin menipisnya sumber energi fosil, maka memanfaatkan limbah sampah tersebut untuk menjadi sumber energi alternatif merupakan solusi dari 2 permasalahan sekaligus, yaitu menumpuknya limbah sampah dan juga keterbatasan sumber energi.

Mesin pembakaran luar (external combustion engine) memiliki kelebihan yaitu dapat memanfaatkan segala jenis bahan bakar. Sehingga mesin-mesin pembakaran luar (external combustion engine) lebih disarankan untuk aplikasi pemanfaatan sumber energi alternatif, termasuk di dalamnya limbah sampah. Mesin stirling merupakan jenis mesin pembakaran luar yang dapat memanfaatkan panas/kalor dari berbagai macam sumber panas/kalor. Penelitian tentang mesin stirling terkait sudah dilakukan oleh beberapa peneliti sebelumnya [3]- [9].

Penelitian ini merupakan pengembangan dari penelitian sebelumnya, dimana pada penelitian sebelumnya dilakukan inovasi desain pada mesin stirling tipe alpha dengan membuat sudut fasa menjadi $180^{\circ}$, dengan tujuan untuk mengurangi pengaruh gravitasi pada saat silinder dingin terkompresi, karena sudut fasa yang sekarang digunakan $\left(90^{\circ}\right)$ memiliki kekurangan yaitu silinder dinginnya yang tegak lurus ke atas, sehingga proses kompresinya melawan gravitasi. Tetapi pada penelitian sebelumnya memiliki kekurangan yaitu pipa generator yang terlalu panjang sehingga menyebabkan banyak kehilangan energi atau panas (heat loss) sehingga kecepatan kompresi menjadi kecil [10], [11]. Sehingga pada penelitian ini melakukan inovasi dan analisa isolasi pipa generator mesin stirling tipe alpha mesin stirling tipe alpha sudut fasa $180^{\circ}$.

\section{METODE}

Untuk melakukan analisa isolasi pipa generator mesin stirling tipe alpha mesin stirling tipe alpha sudut fasa $180^{\circ}$ digunakan metode pendekatan termodinamika dengan teori Schmidt yang dipublikasikan oleh Koichi Hirata [12] dan teori siklus ideal mesin stirling. Untuk melakukan perhitungan-perhitungan tersebut, perlu dilakukan asumsiasumsi sebagai berikut:

Tidak ada pressure loss dan tidak ada perbedaan internal pressure. Proses ekspansi dan proses kompresi berlangsung secara isothermal. Kondisi fluida kerja adalah udara sebagai gas ideal. Terjadi regenerasi sempurna. Volume sisa pada silinder panas menjaga temperatur gas pada silinder panas $\left(\mathrm{T}_{\mathrm{E}}\right)$, volume sisa pada silinder dingin menjaga temperatur gas pada silinder dingin $\left(\mathrm{T}_{\mathrm{C}}\right)$ selama siklus. Temperatur pada regenerator adalah rata-rata temperatur ekspansi $\left(\mathrm{T}_{\mathrm{E}}\right)$ dan temperatur kompresi $\left(\mathrm{T}_{\mathrm{C}}\right)$. Volume ekspansi $\left(\mathrm{V}_{\mathrm{E}}\right)$ dan volume kompresi $\left(\mathrm{V}_{\mathrm{C}}\right)$ berubah berdasarkan fungsi sinusoida.

Simulasi dilakukan dengan menggunakan Ideal Stirling Cycle Calculator, yang diakses secara online. Dengan meginput nilai-nilai yang telah diketahui diatas dan akan didapatkan hasil analisa, grafik P-V dan grafik efisiensi carnot dan mesin stirling dengan temperatur panasnya.

\section{Hasil dan Pembahasan}

\section{A. Simulasi Kalkulasi Siklus Ideal Mesin Stirling}

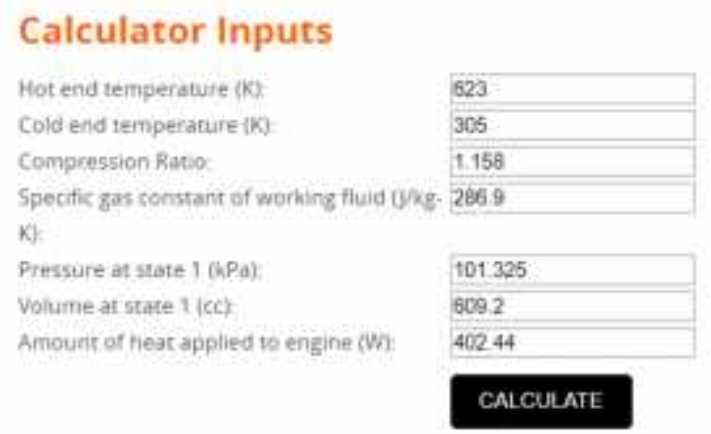

Gambar 1. Input nilai parameter 


\section{Keterangan :}

Compression Ratio $=\frac{V_{\max }}{V_{\min }}=\frac{6,09 \times 10^{-4}}{5,26 \times 10^{-4}}=1,158$

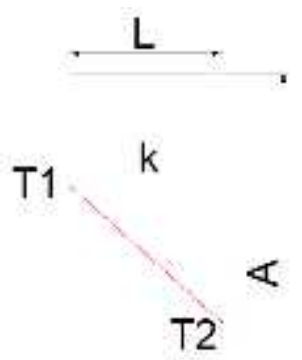

Gambar 2. Skematik perpindahan panas

$$
\begin{aligned}
& \text { Amount of heat }\left(\frac{Q}{t}\right)=k A \frac{(T 1-T 2)}{L} \\
& =20,122 \mathrm{~W} / \mathrm{m}^{\circ} \mathrm{K} \times 0,016 \mathrm{~m}^{2} \frac{(350-349)^{2} \mathrm{~K}}{0,0008 \mathrm{~m}^{2}} \\
& =402,44 \mathrm{Watt}
\end{aligned}
$$

Jumlah kalor yang diaplikasikan ke mesin stirling terjadi pada silinder panas. Bahan yang digunakan menggunakan Pipa Stainless Steel 304 dengan diameter 50,5 $\mathrm{mm}$ dan ketebalan 0,8 $\mathrm{mm}$. Nilai konduktivitas termal bahan dilihat pada tabel A-3 pada buku "Heat Transfer" karya Yunus A. Cengel [13]. Dengan menginterpolasi antara suhu $600^{\circ} \mathrm{K}$ dan $800^{\circ} \mathrm{K}$, didapatkan nilai konduktivitas termal pada suhu $623^{\circ} \mathrm{K}$ adalah $20,122^{2} \mathrm{~W} / \mathrm{m}^{\circ} \mathrm{K}$. Luas permukaan yang menjadi media perpindahan panas konduksi dihitung dari luas permukaan selimut dari silinder panas, yaitu $0,016 \mathrm{~m}^{2}$.

\begin{tabular}{|c|c|}
\hline Calculation Starus in purs OK & \\
\hline Preaicted Frequency (RPM) & 1305 \\
\hline Predisted Power out (W) & 205.4 \\
\hline Fredicted Efficiency (0-1) & 05104 \\
\hline Predicted Average Pressure (kPa) & 1660 \\
\hline Swept Voiume (ce) & $92: 12$ \\
\hline Mass of Working Fuld (mos) & 7054 \\
\hline Work Dut Per Cycletn & 9.441 \\
\hline $\begin{array}{l}\text { Predicted Specific Work out Per Cycle } \\
\text { Oimg-working fluid) }\end{array}$ & 0.01338 \\
\hline Volume at \$rate 1 (cc) & 6092 \\
\hline Absolute Pressure at 5 tate 1 ( $\mathrm{kPa}$ ) & 1013 \\
\hline Temperature at State 1 (ik) & 305.0 \\
\hline volume ac State 2 (ct) & 526.1 \\
\hline Absclute pressure as state 2 (KPa) & 1173 \\
\hline Temperature ar state 2 ik & 3050 \\
\hline volume at 5 tate $3(c c)$ & 3251 \\
\hline Absolute Pressure at State J (d9) & 2397 \\
\hline Temperature at State $3(0)$ & 623.0 \\
\hline Volumeat state 4 (cc) & 6092 \\
\hline Absplure Pressure at Scate 4(kPa) & 2070 \\
\hline Temperature as Srate 4 ( $K$ ) & 6230 \\
\hline
\end{tabular}

Kemudian hasil dari Ideal Stirling Cycle Calculator adalah sebagai berikut:

\section{Calculator Outputs}

Gambar 3. Hasil analisa ideal stirling cycle calculator 
Hasil tersebut memprediksi bahwa mesin stirling yang dirancang mampu berputar hingga 1305 Rpm dan menghasilkan daya output hingga 205,4 Watt. Hubungan grafik antara tekanan (P) dengan volume (V), dan grafik antara efisiensi mesin stirling ideal $(\eta)$ dengan temperatur panasnya $\left(\mathrm{T}_{h}\right)$ adalah sebagai berikut :

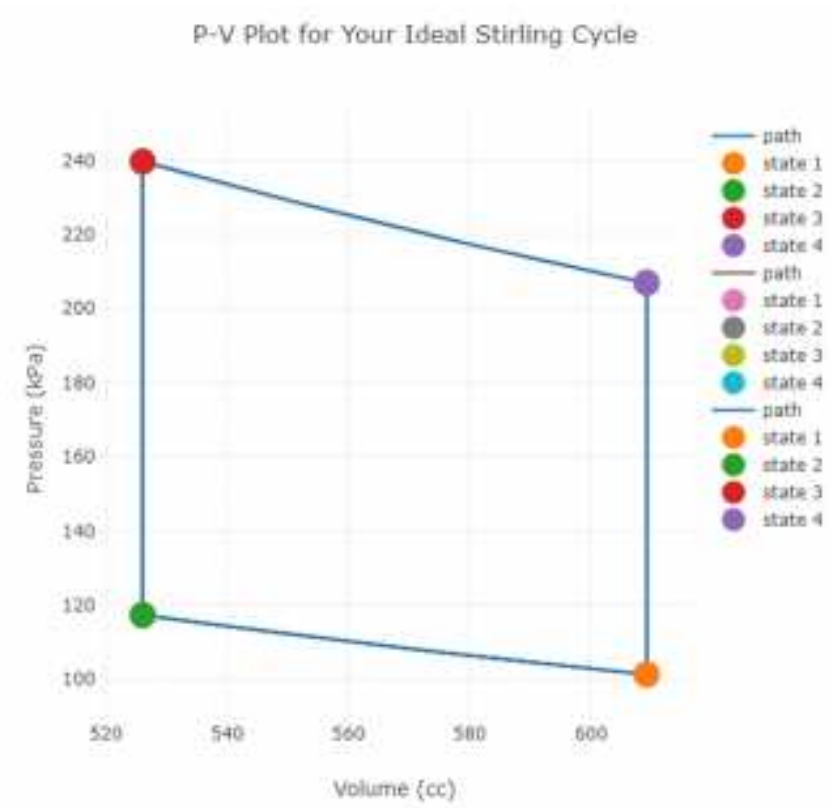

Gambar 4. Grafik diagram $P$ - V siklus ideal

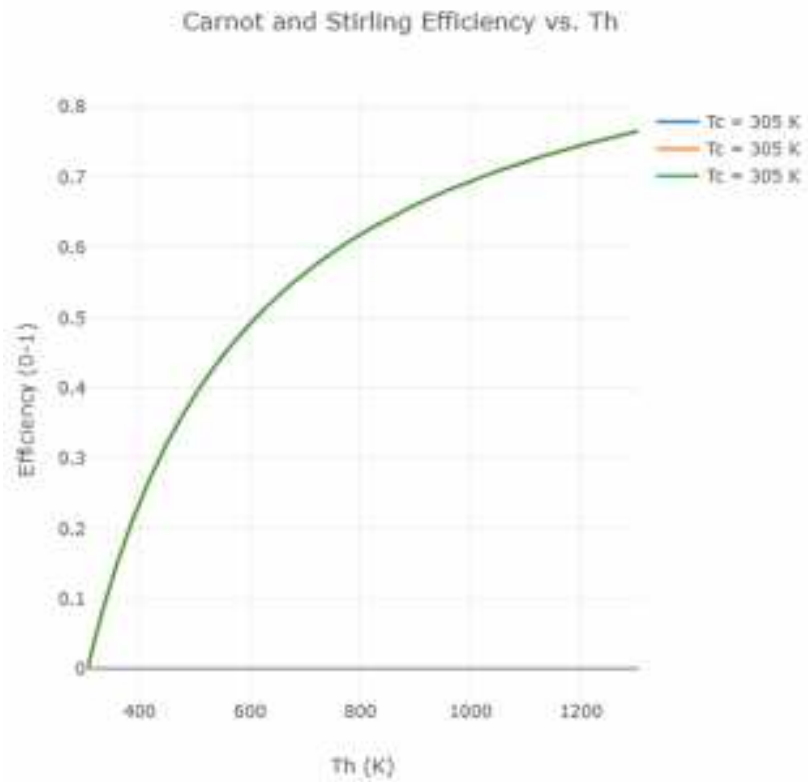

Gambar 5. Grafik efisiensi Carnot dan stirling - temperatur panas

Dapat dilihat dari grafik pada gambar 5 , bahwa $\Delta_{\text {Temperatur berbanding lurus dengan efisiensi thermal. Dan }}$ efisiensi juga berbanding lurus dengan daya. 


\section{B. Analisa Isolasi Pipa Generator}

Pada analisa isolasi pipa generator ini bahan dan dimensi dari pipa generator dilakukan perhitungan ulang dengan tujuan untuk mengurangi kehilangan energi atau panas (heat loss) sehingga kecepatan kompresi menjadi kecil, parameter-parameter tersebut adalah sebagai berikut:

1. Pipa generator menggunakan pipa tembaga ukuran $5 / 8$ " $(15 \mathrm{~mm})$ dengan tebal $0,71 \mathrm{~mm}$.

2. Isolasi pipa menggunakan Armaflex superloen 5/8" dengan tebal $9 \mathrm{~mm}$.

3. Panjang pipa generator yang digunakan adalah $1,22 \mathrm{~m}$

4. Luas permukaan pipa ;

$$
\mathrm{A}=2 \pi \mathrm{r} \times \mathrm{L}=2(3,14) 0,0075 \times 1,22=0,057462 \mathrm{~m}^{2}
$$

5. $\mathrm{R}_{1}=0,01429 \mathrm{~m} ; \mathrm{R}_{2}=0,015 \mathrm{~m} ; \mathrm{R}_{3}$ Isolasi $9 \mathrm{~mm}=0,024 \mathrm{~m}$.

6. $\mathrm{k}$ superlon $=0,036 \mathrm{~W} / \mathrm{mK} ; \mathrm{k}$ tembaga $=385 \mathrm{~W} / \mathrm{mK} ; \mathrm{k}$ udara $=0,026 \mathrm{~W} / \mathrm{mK}$.

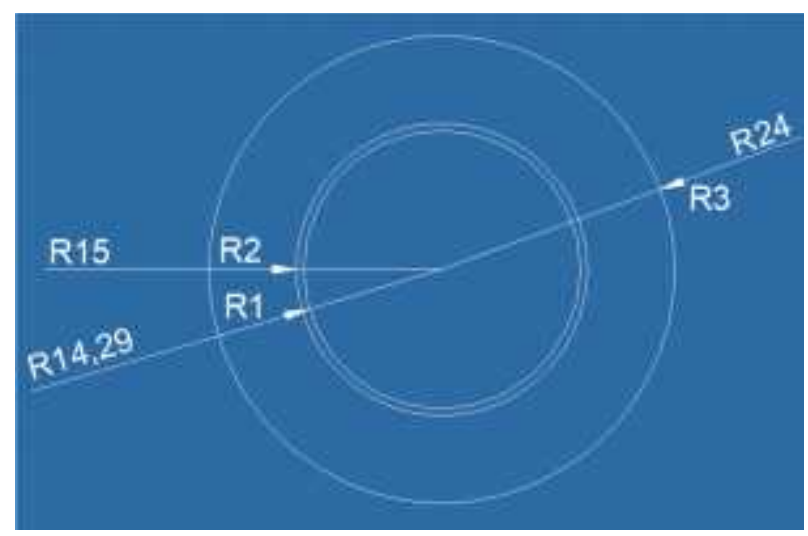

Gambar 6. Dimensi pipa generator

\section{Menghitung Heat Loss}

a) Menentukan nilai kehilangan panas (Q) pada pipa dengan temperatur $420{ }^{\circ} \mathrm{C}$ tidak menggunakan isolasi $\mathrm{Q}=2 \pi \cdot \mathrm{k} . \mathrm{L}(\mathrm{Ta}-\mathrm{Tu}) \ln \mathrm{R}_{2} \mathrm{R}_{1}$

$=2 \pi \times 0,026 \times 1,22(693-307) \ln 0,0150,01429$

$=0,199(386) \ln 1,049$

$=76,8140,04849$

$=1.584,12 \mathrm{~W}$

b) Menentukan nilai kehilangan panas (Q) pada pipa dengan temperatur $420{ }^{\circ} \mathrm{C}$ menggunakan isolasi armaflex superlon $9 \mathrm{~mm}$

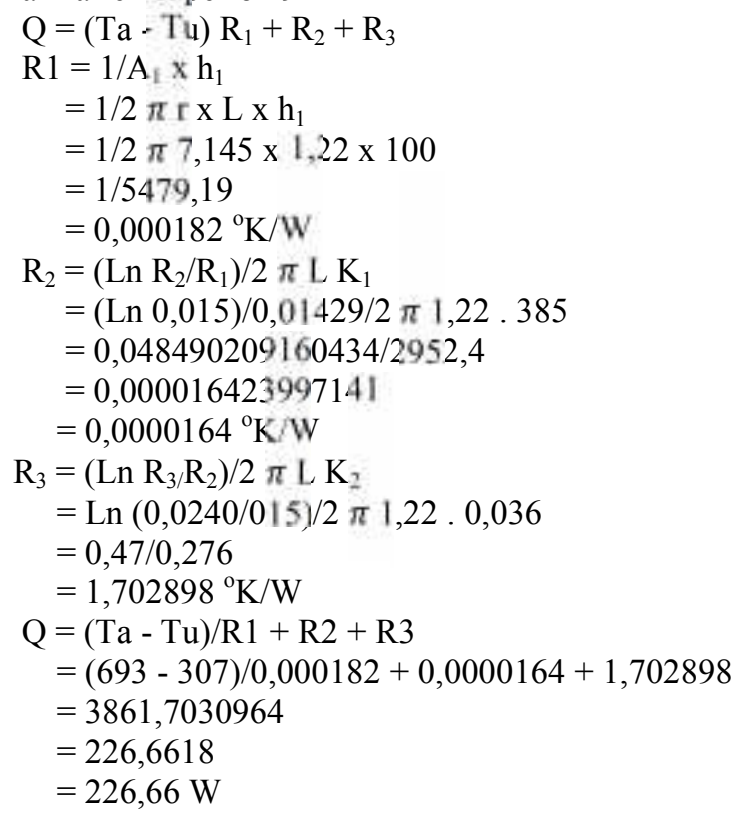




\section{Analisa Heat Loss yang Terjadi}

Setelah didapat hasil kehilangan panas yang terjadi pada pipa generator maka dapat dilihat pada grafik pada gambar 7 dibawah ini.

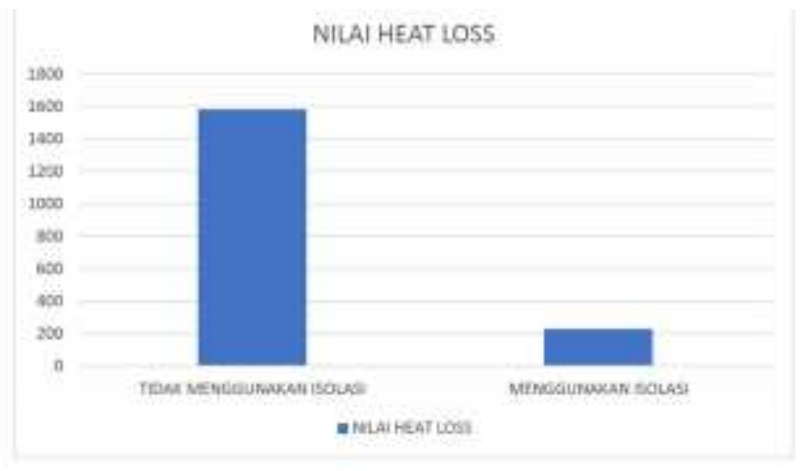

Gambar 7. Perbedaan nilai heat loss menggunakan isolasi dengan tidak menggunakan isolasi

Dari grafik 7 diatas maka dapat dianalisa bahwa bahan isolasi dapat mengurangi kehilangan panas yang terjadi sehingga siklus menjadi efektif.

\section{KESIMPULAN}

Pemberian isolasi pada pipa generator mesin stirling tipe alpha mesin stirling tipe alpha sudut fasa $180^{\circ}$ terbukti dapat mengurangi banyak kehilangan energi atau panas (heat loss) akibat pipa generator yang terlalu panjang, dengan perbandingan nilai heat loss $226,66 \mathrm{~W}$ untuk pipa generator yang menggunakan isolasi yang nilainya juah lebih kecil dibandingkan nilai heat loss ketika pipa generator tanpa menggunakan isokasi yaitu $1.584,12 \mathrm{~W}$.

\section{UCAPAN TERIMA KASIH}

Penulis mengucapkan banyak terimakasih kepada LPPM Untirta dan Fakultas Teknik Untirta yang telah membiayai peneletian ini sehingga penelitian bias berjalan dengan baik.

\section{REFERENSI}

[1] C. Lewis, Biological Fuel. London: Arnold, 1983

[2] Iswanto et al., "The Effect of Additive on Pertalite to Increase Motorcycle Fuel Efficiency". International Journal of Emerging Trends in Engineering Research, vol. 8, no. 8, pp. 4052-4055, 2020, doi: https://doi.org/10.30534/ijeter/2020/04882020.

[3] V. Gehlot, A. Nigam, and K. Marmat, "Development and fabrication of Alpha Stirling Engine," OSR J. Mech. Civ. Eng., vol. 11, no. 6, pp. 69-71, 2014.

[4] A. Bhagat, A. Modi, P. Hinganikar, P. Tambekar, N. Kakade, and B. Kale, "Design of Alpha Stirling Engine in Conjunction with Solar Concentrator," Int. Res. J. Eng. Technol, vol. 3, no. 4, pp. 1109-1114, 2016.

[5] C. Roldan, P. Pieretti, and L. Rojas-Solorzano, "Conceptual And Basic Design Of A Stirling Engine Prototype For Electrical Power Generation Using Solar Energy," ASME, pp. 1-11, 2010.

[6] F. Siddiqui, N. Hayat, M. Farhan, M. Farooq, and H. Bilal, "Effect Of Phase Angle On The Efficiency Of Beta Type Stirling Engine,” J. Fac. Eng. Technol., vol. 22, no. 2, pp. 99-109, 2015.

[7] I. Yuliyani and M. Irwan, "Pembuatan dan Pengujian Prototipe Mesin Stirling Tipe Gamma," IRWNS, vol. 215-219, 2013.

[8] A. Syafriyudin, A. Susastriawan, M. Sabdulah, and F. Gulo, "Pembangkit Listrik Tenaga Panas Matahari Berbasis Mesin Stirling Untuk Skala Rumah Tangga,” J. Teknol., vol. 6, no. 2, pp. 187-192, 2013.

[9] Z. Alvianti, "Desain Dan Pembuatan Mesin Stirling Tenaga Matahari Dengan Memanfaatkan Pemanas Matahari Tipe Box Untuk Pembangkit Listrik,” UIN Maulana Malik Ibrahim, 2016. 
[10] D. Satria, S. Susilo, R. Lusiani, and Y. Hermawan, "Design of alpha type stirling machine biomass-based innovation design with the capacity of 100 watt," 2019, doi: 10.1088/1757-899X/673/1/012124.

[11] D. Satria, R. Lusiani, E. Listijorini, A. Aswata, and Y. Hermawan, “Analisa Performa Mesin Stirling Tipe Alpha Inovasi Desain Berbasis Biomassa,” J. Rekayasa Mesin, vol. 15, no. 1, pp. 33-41, 2020, doi: http://dx.doi.org/10.32497/jrm.v15i1.1839.

[12] K. Hirata, Schmidt Theory for Stirling Engines. Tokyo: Musashimurayama.

[13] Y. A. Cengel, Heat Transfer-A Partical Approach, 2th editio. New York: Mc Graw-Hill inc, 2003. 